\title{
Gastrointestinal Endoparasite Infection on Red Foot (Chelonoidis carbonaria) in Surabaya City Based on Fecal Examination
}

\author{
${ }^{1)}$ Nurin Ardhiani, ${ }^{2)}$ Endang Suprihati@ ${ }^{2)}$ Aditya Yudhana, ${ }^{3)}$ Faisal Fikri \\ ${ }^{1)}$ Student, Faculty of Veterinary Medicine, Universitas Airlangga, nurinardhianisiregar@gmail.com \\ ${ }^{2)}$ Division of Veterinary Parasitology, Faculty of Veterinary Medicine, Universitas Airlangga \\ ${ }^{3)}$ Division of Basic Medical Science, Faculty of Veterinary Medicine, Universitas Airlangga
}

Corresponding author: esuprihati@yahoo.co.id

\begin{abstract}
Infectious disease which caused by parasite is the most serious problem in tortoise breeding. This study identifies gastrointestinal endoparasites infection on Red Foot (Chelonoidis carbonaria) during November 2020 to February 2021 in Surabaya City. Fecal samples from a tortoise, a total of 14 tortoises were collected and examined by native, sedimentation and floatation methods for parasitic eggs and oocyst. Fecal samples for this research were collected from breeding farm in Surabaya City. Data obtained from this study were presented descriptively and analyzed by Chi-Square test. Based on examination results, the occurrence of gastrointestinal endoparasite infection on Red foot was recorded at $100 \%$ from the total samples. The gastrointestinal parasites were identified as helminths and protozoa namely which is dominately by Tachygonetria spp. (14\%), Angusticaecum spp. (3\%), and Balantidium coli $(2 \%)$ respectively. The provision of deworming medication as a curative measure by the owner is carried out regularly and continuously on tortoises that are positively infected with gastrointestinal endoparasites and prevention can be done by paying attention to the management and cleanliness of the cage to prevent potential transmission of endoparasites from the environment to the tortoise.
\end{abstract}

Keywords: Chelonoidis carbonaria, endoparasite, gastrointestinal, Surabaya city, tortoise, fecal examination.

\section{Introduction}

Red foot (Chelonoidis carbonaria) is one of the tortoises that is widely kept because of its uniqueness, such as the presence of a shell pattern that protects the body from tortoises. The upper shell is called the carapace and the lower part is called the plastron (Kendrick and Ades, 2009; Broin et al., 2006). Tortoises vary in size and weight depending on the species, from a few centimeters to 2 meters in length and weigh from 3 until $900 \mathrm{~kg}$. Among the tortoise species, the Red foot has the widest distribution which found in South American countries and in almost all the Caribbean Islands, including Grenada. Red foot prefers habitats with temperatures between $20^{\circ} \mathrm{C}-30^{\circ} \mathrm{C}$ (Springer et al., 2020).

Gastrointestinal endoparasites were commonly found in wild and domesticated tortoises, such as Nematodes, Cestodes,

Trematodes and Protozoa (Rataj et al., 2011). Several gastrointestinal endoparasites were reported with zoonotic potential and may have serious effects on human health (Springe et al., 2020). Gastrointestinal endoparasites have been reported in various chelonian species including Geochelone elegans and Testudo Gracea (Arabkhazaeli et al., 2018), also Chelonoidis spp. in the Galapos Islands (Fournie et al., 2015).

Gastrointestinal endoparasites have been reported in captive bred tortoises in Europe with a high prevalence rate at $43-82 \%$. The examination of 1002 tortoises in Germany also showed parasite infection from Oxyuridae (43.18\%) and also Angusticaecum spp., Balantidium spp., Strongyloides spp., and Heterakis spp. (Hallinger et al., 2018). Moreover, the Greek tortoise was also found to be infected with Oxyuridae and Ascarididae (Yildirimhan et al., 2018).

Gastrointestinal parasites are usually diagnosed by examining tortoise fecal sample (Hedley, 2013). Gastrointestinal endoparasitic infections can cause a lot of threat to tortoise owners. The negative impacts which caused by endoparasite infection are death, acute illness 
and reduced productivity including decreased growth rate (Swai et al., 2006). The prevalence of parasitic infection may be influenced by several factors such as distribution of the host, environment, general conditions of the host and climate (Farjana et al., 2008). Common host factors such as age, sex, breed and feed can also be a factor for parasite distribution. Lack of routine inspections and management will lead to the worst condition in tortoises (Permin and Ranvig, 2001).

Surabaya City which located at East Java Province has been recorded with a large number of reptile lover communities including tortoises, in which proven by there are also many tortoise breeding farms. To our knowledge, there was no study regarding the incidence or prevalence rate of gastrointestinal endoparasite infection in tortoises in Surabaya City, East Java Province. Therefore, it is necessary to conduct present study in order to adding scientific data regarding the initial report of gastrointestinal endoparasite infection in tortoises.

\section{Materials and Methods}

The study design was perform the identification and morphology of gastrointestinal endoparasites on Red foot tortoises located at Surabaya City for a period of 4 months, starting November 2020 until February 2021. The study was conducted by examining the fecal samples using direct native, sedimentation, and floating methods. The data was analyzed in order to identify gastrointestinal endoparasites which found in standard fecal examination. All results that has been found during examination was recorded and presented descriptively.

\section{Results and Discussion}

The prevalence of gastrointestinal endoparasite infection on Red foot tortoises in Surabaya City was recorded at $100 \%$. Those results were categorized as very high compared to other areas, such as the prevalence of endoparasite infection in Red foot from Grenada, which indicating gastrointestinal parasite infection with a total of $14.6 \%$ prevalence rate (Springer et al., 2020). The results of present study were showed in Table 1.

The eggs of Tachygonetria spp. were found in a total of 14 samples. The case of infection from the Nematode parasite which frequently found are from Tachygonetria spp. and Angusticaecum spp. and has been reported in herbivorous reptiles with $43-62 \%$ prevalence rate (Hallinger et al., 2019). The pathogenicity of Tachygonetria spp. in the colon is causing small erosions of the mucosa and in severe condition this can be widespread accompanied by an inflammatory response, and also perineal irritation which usually caused by the presence of adult female worms that lay eggs (Urquhart et al., 2003). The egg of Tachygonetria spp. was symmetrical oval with a develop ova inside (Fig. 1).

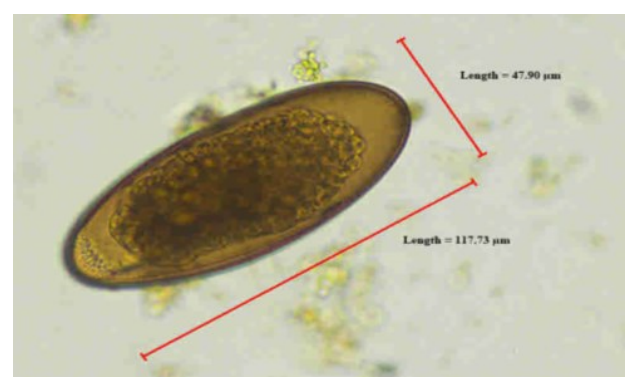

Figure 1. The egg of Tachygonetria spp. (40ox magnification; floatation method).

Table 1. The prevalence rate of gastrointestinal parasites on Red foot (Chelonoidis carbonaria) in Surabaya City during November 2020-February 2021.

\begin{tabular}{lccc}
\hline & Sample (n) & $\begin{array}{c}\text { Positive } \\
\text { Result (\%) }\end{array}$ & $\begin{array}{c}\text { Negative Result } \\
(\%)\end{array}$ \\
\hline Red foot & 14 & $14(100 \%)$ & o (o\%) \\
- Tachygonetria spp. & & $9(64.2 \%)$ & \\
- Tachygonetria + Balantidium coli & & $2(14.2 \%)$ & \\
- Tachygonetria + Angusticaecum & & $3(21.4 \%)$ & \\
- Hatchling & 5 & $5(100 \%)$ & o (o\%) \\
- Tachygonetria & & $1(20 \%)$ & \\
- Tachygonetria + Angusticaecum & & $2(40 \%)$ & \\
- Tachygonetria + Balantidium coli & & $2(40 \%)$ & \\
- Tearling & 9 & $9(100 \%)$ & o (o\%) \\
- Tachygonetria & & $8(88.9 \%)$ & \\
Tachygonetria + Angusticaecum & & $1(11.1 \%)$ & \\
\hline
\end{tabular}


The eggs of Angusticaecum spp. were found in a total of 3 samples. Angusticaecum spp. is one of the parasite from Ascarididae which frequently found infecting tortoises. The infection rate of Angusticaecum spp. in Germany was reported at $0.1 \%$ (Hallinger et al., 2018). Angusticaecum spp. also previously reported in the Russian tortoise (Testudo horsfieldii) and the tortoise marginata (Testudo marginata) (Bunkowska et al., 2011). The egg of Angusticaecum spp. has a slightly rounded oval shape when compared to Tachygonetria spp. and has a thick outer layer (Fig. 2).

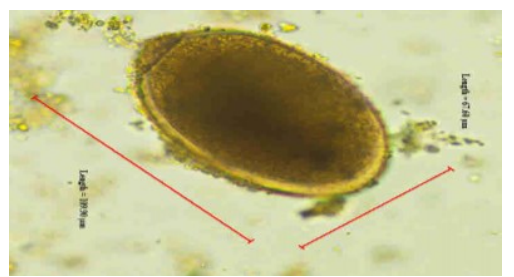

Figure 2. The egg of Angusticaecum spp. (40ox magnification; sedimentation method).

The trophozoites of $B$. coli were found in a total of 2 samples. Balantidium coli also previously reported in Hermann's tortoise (Testudo hermannni) and Centrochelys sulcata in Germany, with prevalence rate recorded at of $0.007 \%$ (Hallinger et al., 2018). Greek tortoises in Morocco also reported with a case of $B$. coli infection (Laghzaoui et al., 2021). The trophozoites were found with an oval shape that tends to be rounded with ciliated walls (Fig. 3).

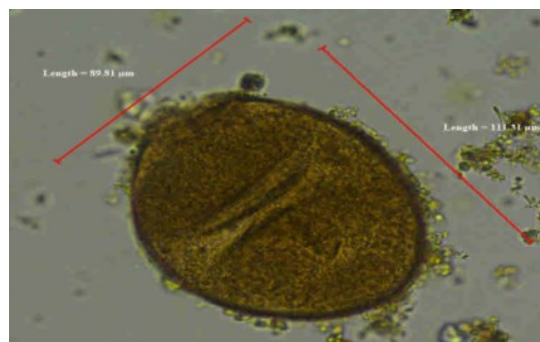

Figure 3. The trophozoite of B. coli (40ox magnification; sedimentation method).

Based on the results of present study, it was found that there was $100 \%$ prevalence rate in all 14 samples with the age category of hatchling and yearling. Those results may be caused by inproper management system in tortoise breeding farm. Several Red foot breeders still apply a conventional cage system with soil mats that tend to be moist, which is beneficial for the development of gastrointestinal endoparasites in the environment and also direct feeding without being given a base or container so that it has the potential contaminated with infective larvae from the environment. Deworming schedule that routinely never given was also contributes as risk factor for the tortoise in being infected by gastrointestinal endoparasites.

In accordance with the report of Bunkowska et al., 2011 in a study where located at Poland, Zoology Garden, Wroclaw City, state that tortoises which kept in an outdoor captivity cage were more susceptible to gastrointrstinal parasite infection. Based on the results, there was zoonotic potential which caused by $B$. coli. The protozoan parasite $B$. coli play role in causing enteritis clinical sign which may lead to intestinal ulceration not only in animals but also humans (Mufasirin et al., 2016). Balantidium coli is a ciliated protozoan that causes balantidiasis in various hosts such as pigs, ruminants, horses and humans. Balantidiasis has a cosmopolitan distribution with a high incidence in the tropics and sub-tropics. Infected hosts will show clinical symptoms of anorexia, dehydration, watery diarrhea and decreased growth rate. Fecal examination can be performed to identify cysts and trophozoites stage of $B$. coli. (Ahmed et al., 2020). The recent case of balantidiasis was reported from China in a 68 years old man with clinical symptoms of abdominal pain, tenesmus, diarrhea, and dysentery which was suspected to be caused by B. coli. (Yu et al., 2020).

\section{Conclusions}

Based on the identification of gastrointestinal endoparasite infection in Red foot (Chelonoidis carbonaria) during November 2020 until February 2021, the prevalence rate of gastrointestinal endoparasite infection was recorded at $100 \%$ from the total of 14 samples. Gastrointestinal endoparasites identified were from helminth and protozoa which dominated by Tachygonetria spp. (14\%), Angusticaecum spp. (3\%), and B. coli (2\%) respectively. Balantidium coli are categorized as zoonotic gastrointestinal endoparasites. Therefore, deworming program as a treatment measure and regular health examination in infected tortoise which carried out by the veterinarian should be strengthening. Moreover, prevention measure also should be carried out by the owners through paying attention to the proper tortoise management and proper sanitation procedure of the captivity in order to break the 
potential transmission of endoparasites from the environment.

\section{References}

Ahmed, A., Ijaz, M., Ayyub, R. M., Ghaffar, A., Ghauri, H. N., Aziz, M. U., \& Javed, M. U. 2020. Balantidium coli in domestic animals: An emerging protozoan pathogen of zoonotic significance. Acta tropica, 203: 105298.

Broin, F.D.L.D., Bour, R., and Perälä, J. 2006. Morphological definition of Eurotestudo (Testudinidae, Chelonii): Second Part In Annales de paléontologie 92(4): 335-357.

Farjana, T., K.R. Islam and M.H. Mondal. 2008. Population Density of Helminths in Ducks : Effects of Host Age, Sex, Breed. Bangladesh Veterinary Journal. 6: 45-51.

Fournie, G., Goodman, S.J., Cruz, M., Cedeno, V., Veles, A., Patino, L., Millins, C., Gibbons, L.M., Fox, M.T., Cunningham, A.A. 2015. Biogeography of parasitic nematode Communities in the Galapagos giant tortoise: Implications for Conservation Management. PloS One 10 (9): eo135684.

Hallinger, M. J., Taubert, A., Hermosilla, C., \& Mutschmann, F. 2019. Captive Agamid lizards in Germany: Prevalence, pathogenicity and therapy of gastrointestinal protozoan and helminth infections. Comparative immunology, microbiology and infectious diseases, 63:7480.

Hallinger, M. J., Taubert, A., Hermosilla, C., and Mutschmann, F. 2018. Occurrence of health-compromising protozoan and helminth infections in tortoises kept as pet animals in Germany. Parasites $\mathcal{E}$ vectors 11(1): 352 .
Hedley, J., Eatwell, K., and Shaw, D.J. 2013. Gastrointestinal parasitic burdens in UK tortoises: a survey of tortoise owners and potential risk factors. Veterinary Record. 173:525.

Kendrick, R. C., and Ades, G.W.J. 2009. Taxonomic and morphometric analysis of a trade confiscation of turtle shells from Java, Indonesia 4: 1-4.

Mufasirin., Lastuti, N. D. R., Suprihati, E. dan Suwanti, L. T. 2016. Buku Ajar Ilmu Penyakit Protozoa. Fakultas Kedokteran Hewan Universitas Airlangga. Surabaya.

Permin, A. and H. Ranviq. 2001. Genetic resistance to Ascaridia galli infections in chickens. Veterinary Parasitology. 11: 101102.

Rataj, A. V., Lindtner-Knific, R., Vlahovic, K., Mavri, U., and Dovc, A. 2011. Parasites in pet reptiles. Acta Veterinaria Scandinavica, 53: 33.

Springer, C. C., Kinsella, M., Vasuki, V., \& Sharma, R. N. 2020. Gastrointestinal parasitic nematodes in pet red-footed tortoises (Chelonoidis carbonaria) from Grenada, West Indies. Heliyon, 6(6): e04119.

Swai, E.S, D.K Esrony, D.M Kambarage, W.E Moshy and A.N Mbise. 2007. A comparison of seroprevalence and risk factors for Theileria parva and T.mutans in smallholder dairy cattle in the Tanga and Iringa regions of Tanzania. The Veterinary Journal. 174 (2): 390-396.

Urquhart, G. M., Armour, J., Duncan, J. L., Dunn, A. M., and Jennings, F. W. 2003. Veterinary Parasitology $2^{\text {nd }}$ ed. University of Glasgow. Scotland. 